\title{
Micro- and nano-photonics course in Beijing Institute of Technology
}

Bin $\mathrm{Hu}$, Juan Liu

Bin Hu, Juan Liu, "Micro- and nano-photonics course in Beijing Institute of Technology," Proc. SPIE 10452, 14th Conference on Education and Training in Optics and Photonics: ETOP 2017, 104525C (16 August 2017); doi: $10.1117 / 12.2269721$

SDIE Event: 14th Conference on Education and Training in Optics and Photonics, ETOP 2017, 2017, Hangzhou, China 


\title{
Micro- and nano-photonics course in Beijing Institute of Technology
}

\author{
Bin $\mathrm{Hu}^{* a}$, Juan Liu ${ }^{\mathrm{a}}$ \\ ${ }^{\mathrm{a} S}$ School of Optoelectronics, Beijing Institute of Technology, Beijing 100081, China \\ hubin@bit.edu.cn
}

\begin{abstract}
'Micro- and nano-photonics' is a course for PhD candidates in School of Optoelectronics, Beijing Institute of Technology. The aim of the course is to introduce the recent development of micro- and nano-photonics to PhD students of optical engineering. The teaching content includes new branches of photonics, including basic theories and developments of plasmonics, matamaterials, photonics crystals and fibers. Then theoretical analysis of nanophotonics, as well as the simulation methods and software are introduced. The fabrication methods of nanophotonic devices are also introduced. More than $30 \mathrm{PhD}$ students have been taught by this course since 2012. In this paper, we give an introduction about our course and its effects on the students' research. We also give a discussion about how to give class to $\mathrm{PhD}$ students with backgrounds of optics and photonics.
\end{abstract}

Keywords: Micro and nano photonics, PhD student course, advanced optical research education

\section{INTRODUCTION}

Beijing Institute of Technology (BIT), founded in 1940 and be famous of its military technology, is one of the national key universities of China. It is one of the first Chinese universities to run a graduate school and one of the national "Project 211" and "Project 985" universities which are given priority for development by the Chinese government. BIT has now developed into a top science and engineering university in China, and implements a disciplinary development strategy of "reinforcing ground weaponry research, promoting electronic information development, and expanding the aerospace field". BIT has been actively implementing innovative education strategies, emphasizing the importance of "a solid foundation of knowledge, ability promotion, innovativeness and an equal development in both mind and morality".

School of Optoelectronics of BIT was established in 1953 with the original name of Department of Precision Instruments. It is one of the earliest institutions in China to engage in teaching and researching in Optical Engineering. The school has 138 faculty members, including 37 full professors, 49 associate professors, and 780 undergraduate students, 375 Master candidates and $241 \mathrm{PhD}$ candidates. Currently the school has six research directions, including ultra-wide waveband imaging, optoelectronic instruments, visual reality and augment reality, optical design and fabrication, laser and optoelectronics, and information optics. The graduate program, which involves three majors: instrument science and technology, electronic science and technology, optical engineering, emphasizes high quality in graduate education and research, as well as preparing students for a variety of careers in research and advanced development. The school has many courses of optics, photonics, and electronics for $\mathrm{PhD}$ students, including modern development of optics, modern optoelectronic devices and technology of imaging, optoelectronic film and devices, digital color management, design of modern optoelectronic systems, etc.

With the rapid development of micro and nano photonics in physics, material sciences, and optoelectronics in recent years [1-4], the PhD students in the school of optoelectronics have increasing demands of a course for introducing this new branch of optics. The reason is that more and more researchers from all directions of optics realize that micro and nano photonics may benefit their works due to the great development of nano fabrications. In addition, nano-photonics and related topics become being involved in courses of many colleges lately all over the world [5-9]. Therefore, the course of 'micro- and nano- photonics' was started for grade $1 \mathrm{PhD}$ students in 2010. In this paper, we will give an introduction of this course in the school of optoelectronics, including the course content, teaching methods, and the teaching effects. 


\section{MICRO- AND NANO- PHOTONICS COURSE IN BIT}

\subsection{Course content}

One aim of micro- and nano- photonics course of BIT is to introduce the newest development of micro and nano photonics and related physical sciences and technologies. It contains 4 parts, including the overview of micro- and nanophotonics, basic theories and methods, applications of micro- and nano- photonics, fabrications and characterization. The total course have 10 chapters, and it will take 32 class hours. The detailed course content is shown in table 1 . It can be seen that the main content of the course is the basic theories and applications, which takes 24 class hours, accounted for $75 \%$ of the total class hours. The basic theories include 3 chapters. Chapter 2 corresponds to the exact solutions of wave propagation. When the optical device is larger than 10 wavelengths, scalar theories can be applied. When the device is smaller, full wave vector theories are needed, while when the device is smaller than 1 wavelength, effective index theory can be applied. Therefore, these 3 theories are introduced first. For one application of the scalar theory, optical elements design methods are then introduced, which are also well applied in modern photonic devices design. The vector simulation methods are new added in the end of this part because more and more simulation methods are used in nanophotonic devices design recently, due to the reason that there is no exact solution of Maxwell equations for complicated structures. The applications of micro- and nano- photonics include 4 branches of nano-photonics, which are all very popular and have many applications in the past 30 years. In the class, we mainly focus on the development history and basic principles of these new directions rather than the complex theories, in order to not only introduce what this field is, but also lead the students understand how these fields developed and become more and more attractive. At the last part of this course, we give the introduction of main methods of fabrications and characterizations of nano-structures to let the students know how the micro- and nano- photonics devices are made and characterized.

Table 1. Couse content of micro- and nano- photonics course in BIT.

\begin{tabular}{|c|c|c|c|}
\hline Parts & Chapters & Sections & $\begin{array}{l}\text { Class } \\
\text { Hours }\end{array}$ \\
\hline \multirow{2}{*}{$\begin{array}{l}\text { 1. Overview of } \\
\text { micro- and } \\
\text { nano- photonics }\end{array}$} & \multirow{2}{*}{$\begin{array}{l}\text { 1. Overview of micro- and } \\
\text { nano- photonics }\end{array}$} & 1.1. History of micro- and nano- photonics development & \multirow{2}{*}{2} \\
\hline & & 1.2 Introduction of this course & \\
\hline \multirow{15}{*}{$\begin{array}{l}\text { 2. Basic theories } \\
\text { and methods }\end{array}$} & \multirow{3}{*}{ 2. Basic theories } & 2.1 Scalar diffractive theories & \multirow{3}{*}{2} \\
\hline & & 2.2 Vector diffractive theories by Maxwell equations & \\
\hline & & 2.3 Effective index theory & \\
\hline & \multirow{6}{*}{$\begin{array}{l}\text { 3. Scalar diffractive optical } \\
\text { elements design methods }\end{array}$} & 3.1 Introduction of diffractive optical elements & \multirow{6}{*}{5} \\
\hline & & $3.2 \mathrm{G}-\mathrm{S}$ algorithm & \\
\hline & & $3.3 \mathrm{Y}-\mathrm{G}$ algorithm & \\
\hline & & 3.4 Simulated annealing method & \\
\hline & & 3.5 Conjugate gradient method & \\
\hline & & 3.6 Genetic algorithm & \\
\hline & \multirow{6}{*}{$\begin{array}{l}\text { 4. Vector simulation } \\
\text { methods }\end{array}$} & 4.1 Introduction of vector simulation methods & \multirow{6}{*}{5} \\
\hline & & 4.2 Finite difference method & \\
\hline & & 4.3 Finite element method & \\
\hline & & 4.4 Boundary element method & \\
\hline & & 4.5 Finite difference time domain method & \\
\hline & & 4.6 Numerical integration method & \\
\hline
\end{tabular}




\begin{tabular}{|c|c|c|c|}
\hline \multirow{15}{*}{$\begin{array}{l}\text { 3. Applications } \\
\text { of micro- and } \\
\text { nano- photonics }\end{array}$} & \multirow{3}{*}{$\begin{array}{l}\text { 5. Optical waveguides and } \\
\text { fibers }\end{array}$} & 5.1 Introduction of optical fibers & \multirow{3}{*}{3} \\
\hline & & 5.2 Theories of optical fibers & \\
\hline & & 5.3 Micro and nano devices in optical fiber systems & \\
\hline & \multirow{4}{*}{ 6. Photonic crystals } & 6.1 Introduction of photonic crystals & \multirow{4}{*}{3} \\
\hline & & 6.2 Basic theories of photonic crystals & \\
\hline & & 6.3 Applications of photonic crystals & \\
\hline & & 6.4 Photonic crystal fibers & \\
\hline & \multirow{4}{*}{ 7. Plasmonics } & 7.1 Introduction of plasmonics & \multirow{4}{*}{3} \\
\hline & & 7.2 Basic theories of surface plasmon polaritons & \\
\hline & & 7.3 Applications of surface plasmon polaritons & \\
\hline & & 7.4 Surface magneto plasmons & \\
\hline & \multirow{4}{*}{ 8. Metamaterials } & 8.1 Introduction of metamaterials & \multirow{4}{*}{3} \\
\hline & & 8.2 Applications of metamaterials & \\
\hline & & 8.3 Metasurfaces & \\
\hline & & 8.4 Graphene photonics & \\
\hline \multirow{7}{*}{$\begin{array}{l}\text { 4. Fabrications } \\
\text { and } \\
\text { characterization. }\end{array}$} & \multirow{4}{*}{ 9. Nano fabrications } & 9.1 Photolithography & \multirow{4}{*}{3} \\
\hline & & 9.2 Electron beam lithography & \\
\hline & & 9.3 Focus ion beam lithography & \\
\hline & & 9.4 Scanning probe fabrication & \\
\hline & \multirow{3}{*}{ 10. Characterization } & 10.1 Scanning tunneling microscope & \multirow{3}{*}{3} \\
\hline & & 10.2 Atom force microscope & \\
\hline & & 10.3 Scanning near-field optical microscope & \\
\hline
\end{tabular}

\subsection{Teaching methods}

In the past, most of the $\mathrm{PhD}$ course is only given by the teacher from the beginning to the end of one semester in BIT. However, this teaching method becomes more and more inappropriate in the internet age, which is an era of knowledge booming. Nowadays, all the knowledge can be obtained easily on the internet rather than in the class. Therefore, the purpose of this course is not only teaching knowledge, introducing what micro- and nano-photonics is, and the newest development of this field, but also developing the research abilities of the PhD students, including searching ability, selfstudy ability, and summarizing ability of a research direction. Based on this purpose, the course is given by teachers and all the students together. After nearly each chapter, there would be a discussion between the students, and they need to give a presentation to summarize their conclusions.

The chapter of overview is only given by the teachers. We focus on introducing what micro- and nano-photonics is, and what it can be used for. "Novel and interesting applications" that traditional optics cannot do are emphasized, such as negative refraction, invisible cloak, etc.

Part 2 and 4 are mainly given by the teachers because these parts are giving knowledge of theories and experiments. However, in order to enhance the understanding of the knowledge, every student needs to give a presentations on whether theory or experiments, according to their research topic after these two parts.

Part 3 is mainly given by the students. The teacher only give a brief introduction of the 4 newest micro- and nanophotonics branch -- optical waveguides and fibers, photonic crystals, plasmonics, and metamaterials, including basic theory and their development. The introduction of each branch only takes 1 class hours. The students need to search 
corresponding literature and discussion after the class, then every student gives a presentation on each branch. The presentation needs to answer three questions: Why this branch becomes a very hot research spot in recent years? What is the future direction of this branch in your opinion? What will be a new hot spot of your research field in the next five years? These questions are aim to develop the ability of finding the direction of a new research field.

At the end of the course, the teacher evaluate each student and give the score according to each presentations.

\subsection{Teaching effects}

The micro- and nano-photonics course was started in 2010. The student numbers are 6, 8, 5, 5, 11, 8, 4 from 2010 to 2016, correspondingly. The background of the students includes nano-photonics, material science, diffractive optical elements and holography, nanolithography, detection of precision instruments, optical design, and digital imaging processing. According to the student feedback, the course is more helpful to the students of research topic close to micro- and nano-photonics, such as nano-photonics, nanolithography, holography and precision instrument detection. In 2014, one student studying holography conceived a new idea of color holography realization with only one space light modulator based on the discussion of plasmonics. By this idea, he received the PhD grand of BIT.

\section{SUMMARY}

In conclusion, the micro- and nano-photonics course in BIT has been given for 7 years. The course content becomes more and more plentiful. The target of this course is not only give the introduction and knowledge of micro- and nano-

photonics, but also develop the research abilities of $\mathrm{PhD}$ students. We hope this course may develop a new teaching method of PhD students of optoelectronics.

\section{REFERENCES}

[1] W. L. Barnes, A. Dereux, and T. W. Ebbesen, Nature 424, 824 (2003).

[2] E. Ozbay, Science 311, 189 (2006).

[3] T. W. Ebbesen, C. Genet, and S. I. Bozhevolnyi, Phys. Today 61, 44 (2008).

[4] D. K. Gramotnev and S. I. Bozhevolnyi, Nat. Photonics 4, 83 (2010).

[5] M. Nantel, and J. Beda, Seventh International Conference on Education and Training in Optics and Photonics, Proceedings of SPIE 4588, 70, (2002).

[6] M. H.-Wallacea, N. L. Regensa, S. M. Pompea, Seventh International Conference on Education and Training in Optics and Photonics, Proceedings of SPIE 4588, 514, (2002).

[7] G. W. Chang, Z. M. Yeh, H. M. Chang, and S. Y. Pan, IEEE TRANSACTIONS ON EDUCATION, 48, 642, (2005).

[8] M. Nantel, The Ontario Photonics Education and Training Association (OPETA): l'Union fait la Force!, ProceedingETuD5.

[9] N. Massa, et. al, PHOTON PBL: Problem-Based Learning in Photonics Technology Education, ETOP 2007. 